\title{
A molecular epidemiological study of respiratory viruses detected in Japanese children with acute wheezing illness
}

\author{
Asako Fujitsuka ${ }^{1,2}$, Hiroyuki Tsukagoshi ${ }^{3}$, Mika Arakawa ${ }^{4}$, Kazuko Goto-Sugai $^{1,2}$, Akihide Ryo ${ }^{5}$, Yoshimichi Okayama ${ }^{6}$, \\ Katsumi Mizuta ${ }^{7}$, Atsuyoshi Nishina ${ }^{8}$, Masakazu Yoshizumi $^{3}$, Yoichi Kaburagi $^{1}$, Masahiro Noda ${ }^{9}$, Masato Tashiro ${ }^{10}$, \\ Nobuhiko Okabe ${ }^{11}$, Masaaki Mori², Shumpei Yokota ${ }^{2}$ and Hirokazu Kimura ${ }^{3,11^{*}}$
}

\begin{abstract}
Background: Recent studies strongly suggest that some respiratory viruses are associated with the induction of acute wheezing and/or exacerbation of bronchial asthma. However, molecular epidemiology of these viruses is not exactly known.

Methods: Using PCR technology, we attempted to detect various respiratory viruses from 115 Japanese children. Furthermore, the detected viruses were subjected to homology, pairwise distance, and phylogenetic analysis.

Results: Viruses were detected from 99 (86.1\%) patients. Respiratory syncytial virus (RSV) alone and human rhinovirus (HRV) alone were detected in 47 (40.9\%) and 36 (31.3\%) patients, respectively. Both RSV and HRV were detected in 14 (12.2\%) patients. Human metapneumovirus (HMPV) alone and human parainfluenza virus (HPIV) alone were detected in 1 (0.9\%) patient each, respectively. Homology and phylogenetic analyses showed that the RSV and HRV strains were classified into genetically diverse species or subgroups. In addition, RSV was the dominant virus detected in patients with no history of wheezing, whereas HRV was dominant in patients with a history of wheezing.
\end{abstract}

Conclusions: The results suggested that these genetically diverse respiratory viruses, especially RSV and HRV, might be associated with wheezing in Japanese children.

\section{Background}

A range of respiratory viruses are known to cause acute respiratory infections (ARI), including the common cold, bronchiolitis, and pneumonia in humans [1]. The major pathogens are potentially respiratory syncytial virus (RSV), human rhinovirus (HRV), human metapneumovirus (HMPV), human parainfluenza virus (HPIV), enterovirus (EV), influenza viruses ( $\mathrm{InfV})$, adenoviruses (AdV), and human bocavirus ( $\mathrm{HBoV})[2,3]$. Respiratory infections by RSV, HRV, and HPIV are implicated in the induction of wheezing and the exacerbation of asthma, although their mechanisms are not clearly known [4]. The prevalence of asthma in developed

\footnotetext{
* Correspondence: hkimura0511@gmail.com

${ }^{3}$ Department of Health Science, Gunma Prefectural Institute of Public Health and Environmental Sciences, 378 Kamioki-machi, Maebashi-shi, Gunma 3710052, Japan

Full list of author information is available at the end of the article
}

countries is around 10 to $15 \%$ in children, while the prevalence is lower but increasing rapidly in developing countries [5]. Accumulating evidence indicates that the etiology of most cases of asthma, namely virus-induced asthma, is linked to such respiratory virus infections [6-9]. In addition, other epidemiological studies suggest that about $70 \%$ of infants have experienced an RSV infection by the age of 1 year, and $100 \%$ by the age of 2 years; the host response to the virus varies greatly, but includes upper respiratory tract infections, typical bronchiolitis (with crepitations but no wheeze), and RSV-induced wheezy bronchitis [10,11]. In addition, HRV includes over 100 serotypes and most of these are epidemic, although their epidemiology is not known [12]. Similarly, most children are infected at least once with HPIV early in life, but reinfections occur throughout life [13]. HBoV and HMPV are recently discovered

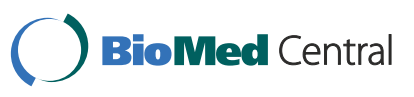


agents of ARI, and these viruses are also associated with the common cold, bronchiolitis, and pneumonia [14]. However, the relationships between these viruses and virus-induced wheezing are not exactly known.

Genetic analyses including sequence and phylogenetic analyses of various viruses enable detailed genetic characterization of these agents. With the use of these methods, detailed molecular epidemiological studies have been reported, even in non-culturable viruses such as HRV species C (HRV-C) or HBoV $[15,16]$. However, molecular epidemiology of various respiratory viruses with regard to virus-induced asthma is not exactly known. From these backgrounds, we detected various respiratory viruses and performed a molecular epidemiological study of them in Japanese children with acute wheezing illness.

\section{Methods}

\section{Subjects}

One hundred fifteen wheezy Japanese children were enrolled in the present study. A summary of patient data is shown in Table 1. All patients visited the National Hospital Organization Yokohama Medical Center from November 2007 to March 2009. Of these patients, 39 had a history of wheezing, while the other 76 patients had no such history. In addition, 66 patients had viral bronchitis and/or bronchiolitis at consultation. These patients were treated with infusion, oxygen, and $\beta 2$-agonist or epinephrine nebulization. Informed consent was obtained from the parents of all subjects for the donation of the nasopharyngeal swabs used in this study.

\section{DNA/RNA extraction, PCR, and sequencing}

For viral DNA/RNA extraction, RT-PCR, and sequence analysis, nasopharyngeal swab samples were centrifuged at $3000 \times \mathrm{g}$ at $4^{\circ} \mathrm{C}$ for $15 \mathrm{~min}$, and the supernatants were used for RT-PCR and sequence analysis as described previously [17]. Viral nucleic acid was extracted from the samples using the High Pure Viral
Nucleic Acid Kit (Roche Diagnostics, Mannheim, Germany). The reverse transcription reaction mixture was incubated with random hexamers at $42^{\circ} \mathrm{C}$ for $90 \mathrm{~min}$, followed by incubation at $99^{\circ} \mathrm{C}$ for $5 \mathrm{~min}$, and then amplification by thermal cycling. The PCR procedures for amplification of various viral genes including RSV [18], HRV [19,20], HMPV [21], HPIV [22], EV [19,20], InfV [23], AdV [24], and $\mathrm{HBoV}$ [25] were conducted as previously described. The primers for PCR are shown in Table 2. To avoid carry over and cross-contamination in PCR, the extraction of viral RNA/DNA was conducted in a room physically separate from that used for performing PCR. Furthermore, positive and negative controls were included in all PCR assays. PCR products were determined by electrophoresis on 3\% agarose gel. Purification of DNA fragments and nucleotide sequence determination procedures were performed as described previously [17].

\section{Phylogenetic analysis and calculation of pairwise distances}

We performed homology and phylogenetic analysis of the $G$ gene of RSV, and the $V P 4 / V P 2$ coding region of HRV, because these viruses were the most commonly detected strains. The nucleotide positions of the nucleotide positions of the $G$ gene of RSV were 673-912 (240 bp, for subgroup A) or 670-963 (294 bp, for subgroup B), and the VP4/VP2 coding region of HRV were 623-1012 (390 bp). We used the CLUSTAL W program on the DNA Data Bank of Japan (DDBJ) homepage http://clustalw. ddbj.nig.ac.jp/top-j.html and TreeExplorer (Version 2.12) http://evolgen.biol.metro-u.ac.jp/TE/. Evolutionary distances were estimated using Kimura's two-parameter method, and phylogenetic trees were constructed using the neighbor-joining (NJ) method [26]. The reliability of the tree was estimated using 1000 bootstrap replications. We selected the reference strains as previously described to construct the phylogenetic trees of RSV and HRV

Table 1 Subject data in this study

\begin{tabular}{|c|c|c|c|c|c|c|c|c|c|c|c|}
\hline \multirow[t]{2}{*}{$\begin{array}{l}\text { No. of } \\
\text { patients }\end{array}$} & \multirow[t]{2}{*}{$\operatorname{Sex}(M / F)$} & \multirow[t]{2}{*}{$\begin{array}{c}\text { Age } \\
\text { (months) }\end{array}$} & \multirow{2}{*}{$\begin{array}{l}\text { History of } \\
\text { wheezing } \\
\text { and/or } \\
\text { asthma }\end{array}$} & \multirow[t]{2}{*}{$\begin{array}{c}\text { No. of } \\
\text { patients }\end{array}$} & \multirow[t]{2}{*}{$\operatorname{Sex}(M / F)$} & \multirow[t]{2}{*}{$\begin{array}{c}\text { Age } \\
\text { (months) }\end{array}$} & \multicolumn{2}{|c|}{$\begin{array}{c}\text { No. of } \\
\text { inpatients and } \\
\text { outpatients }\end{array}$} & \multirow{2}{*}{$\begin{array}{l}\text { No. of cases of } \\
\text { bronchitis and/ } \\
\text { or bronchiolitis } \\
46^{*}\end{array}$} & \multirow{2}{*}{$\begin{array}{c}\begin{array}{c}\text { Age } \\
\text { (months) }\end{array} \\
13.5 \pm 21.0\end{array}$} & \multirow{2}{*}{$\begin{array}{c}\begin{array}{c}\text { Hospitalization } \\
\text { (days) }\end{array} \\
7.1 \pm 2.5\end{array}$} \\
\hline & & & & & & & inpatients & $55^{*}$ & & & \\
\hline & & & No & 76 & $44 / 32$ & $\begin{array}{c}16.9 \pm \\
23.9\end{array}$ & & & & & \\
\hline \multirow[t]{4}{*}{115} & $70 / 45$ & $20.8 \pm 25.7$ & & & & & outpatients & 21 & 7 & $25.9 \pm 28.9$ & \\
\hline & & & & & & & inpatients & 16 & 8 & $18.1 \pm 17.0$ & $7.1 \pm 1.2$ \\
\hline & & & Yes & 39 & $26 / 13$ & $\begin{array}{c}28.5 \pm \\
27.5^{*}\end{array}$ & & & & & \\
\hline & & & & & & & outpatients & 23 & 5 & $35.7 \pm 31.3$ & \\
\hline
\end{tabular}

Data are expressed as mean \pm SD

M/F: male/female

${ }^{*} p<0.05$ 
Table 2 Primers for PCR used in this study

\begin{tabular}{|c|c|c|c|}
\hline Virus & Primer & Sequence & $\begin{array}{c}\text { Reference } \\
\text { no. }\end{array}$ \\
\hline \multirow[t]{4}{*}{ RSV } & ABG490 & 5'-ATGATTWYCAYTTTGAAGTGTTC-3' & {$[22]$} \\
\hline & F164 & 5'-GTTATGACACTGGTATACCAA CC-3' & \\
\hline & AG655 & 5'-GATCYCAAACCTCAAACCAC-3' & [23] \\
\hline & BG517 & 5'-TTYGTTCCCTGTAGTATATGT G-3' & \\
\hline \multirow[t]{2}{*}{ HRV } & EVP4 & 5'-CTACTITGGTGTCCGTGTT-3' & [24] \\
\hline & OL68-1 & 5'-GGTAAYTTCCACCACCANCC-3' & [25] \\
\hline \multirow[t]{4}{*}{ HMPV } & hMPV-1f & 5'-CTITGGACTTAATGACAGATG-3' & [26] \\
\hline & hMPV-1r & 5'-GTCTTCCTGTGCTAACTTTG-3' & \\
\hline & hMPV-2f & 5'-CATGCCGACCTCTGCAGGAC-3' & [27] \\
\hline & hMPV-2r & 5'-ATGTTGCAYTCYYTTGATTG-3' & \\
\hline \multirow[t]{6}{*}{ HPIV } & PIS1+ & 5'-CCGGTAATTTCTCATACCTAT G-3' & {$[28]$} \\
\hline & PIS1- & 5'-CTTTGGAGCGGAGTTGTTAAG-3' & \\
\hline & $\mathrm{PIS} 2+$ & 5'-CCATTTACCTAAGTGATGGAAT-3' & \\
\hline & PIS2- & 5'-GCCCTGTTGTATTTGGAAGAGA-3' & \\
\hline & PIS3+ & 5'-ACTCCCAAAGTTGATGAAAGAT-3' & \\
\hline & PIS3- & 5'-TAAATCTTGTTGTTGAGATTG-3' & \\
\hline \multirow[t]{2}{*}{$\begin{array}{l}\ln f V \\
A\end{array}$} & M30F2/08 & $\begin{array}{c}5^{\prime}- \\
\text { ATGAGYCTTYTAACCGAGGTCGAAACG- } \\
3^{\prime}\end{array}$ & {$[29]$} \\
\hline & $\begin{array}{l}\text { M264R3/ } \\
08\end{array}$ & 5'-TGGACAAANCGTCTACGCTGCAG-3' & \\
\hline \multirow[t]{2}{*}{$\operatorname{lnfV} B$} & BHA1F1 & $\begin{array}{c}\text { 5'-AATATCCACAAAATGAAG GCAATA- } \\
3^{\prime}\end{array}$ & [29] \\
\hline & BHAR1166 & 5'-ATCATTCCTTCCСАТССТССТTCT-3' & \\
\hline \multirow[t]{2}{*}{ AdV } & AdnU-S'2 & 5'-TTCCCCATGGCNCACAAYAC-3' & {$[30]$} \\
\hline & AdnU-A2 & 5'-TGCCKRCTCATRGGCTGRAAGTT-3' & \\
\hline \multirow[t]{2}{*}{ HBoV } & $188 \mathrm{~F}$ & 5'-GACCTCTGTAAGTACTATTAC-3' & [31] \\
\hline & $542 \mathrm{R}$ & 5'-CTCTGTGTTGACTGAATACAG-3' & \\
\hline
\end{tabular}

RSV: respiratory syncytial virus; HRV: human rhinovirus; HMPV: human metapneumovirus; HPIV: human parainfluenza virus; InfV A: influenza virus subtype $A$; Inf $B$ : influenza virus subtype $B ; A d V$ : adenovirus; $H B o V$ : human bocavirus

$[17,27]$. Moreover, we calculated subgroup or species frequency distributions using pairwise genetic distances for each strain, as previously described [17].

\section{Statistical analysis}

Data were analyzed using SPSS software (SPSS for Windows, Version 10.0). All data are expressed as mean \pm SD. We performed bivariate analyses using Pearson $\chi^{2}$ and Fisher exact tests to compare the prevalence of respiratory viruses and other variables between the study groups. The Student's $t$-test was used to compare mean age in the study group. Statistical significance was set at the level of $p<0.05$.

\section{Ethics approval}

All samples were collected after written informed consent was obtained from the subjects' parents. The study protocol was approved by the Ethics Committee on Human Research of National Hospital Organization Yokohama Medical Center.

\section{Results}

Viruses detected in the present subjects

We genetically detected RSV, HRV, HMPV, HPIV, EV, InfV, $\mathrm{AdV}$, and $\mathrm{HBoV}$ in samples from 115 Japanese children with acute wheezing (Table 3). RSV alone was detected in 47 patients (40.9\%). Among these, subgroups A (RSV-A) and B (RSV-B) were found in 27 and 20 patients, respectively. HRV alone was detected in 36 patients $(31.3 \%)$, and among these, HRV species $\mathrm{A}$ (HRV-A), B (HRV-B), and C (HRV-C) were found in 17, 2 , and 17 patients, respectively. Both RSV and HRV were detected in 14 patients (12.2\%). Among these, combinations of RSV-A + HRV-A, RSV-A + HRV-B, and RSV-A + HRV-C were found in 5, 1, and 1 patient, respectively. In addition, RSV-B + HRV-A, RSV-B + HRV-B, and RSV-B + HRV-C were found in 2, 1 , and 4 patients, respectively. HMPV alone and HPIV alone were detected in 1 patient each, respectively. Finally, no viral genes for RSV, HRV, HMPV, HPIV, EV, InfV, $\mathrm{AdV}$, and $\mathrm{HBoV}$ were detected in 16 patients (13.9\%). From these data, RSV was revealed to be the dominant species detected in patients with no history of wheezing and/or asthma (38 patients vs. 9 patients, $p<0.05$ ), while HRV was dominant in those with a history of wheezing and/or asthma (12 patients vs. 24 patients, $p<0.05$ ). These results suggested that RSV and HRV were the major causative agents of acute wheezing in the present study. Moreover, both RSV and HRV were detected in over $10 \%$ of patients with acute wheezing.

\section{Seasonal variations of detected viruses}

To address relationships between seasonal variations of respiratory viruses and acute wheezing, we showed detected viruses during investigation period as Figure 1. Prevalence of RSV was found from autumn to winter, while prevalence of HRV was found in all season. In addition, both viruses were detected from autumn to winter.

\section{Homology, phylogenetic analysis, and pairwise distances of RSV and HRV}

We performed phylogenetic and homology analysis, and calculated the pairwise distances of RSV and HRV in the present cases. The phylogenetic tree based on $G$ gene of RSV, and the VP4/VP2 coding region of HRV are shown in Figure 2 and 3. The homology and pairwise distances are shown in Table 4. First, the RSV was classified into two subgroups, A and B. In addition, strains belonging to both subgroups were subdivided into three genotypes (GA2, GA5, and BA, Figure 2). HRV was classified into three species: HRV-A, -B, and -C. Strains belonging to these species were subdivided into many clusters in the phylogenetic tree (Figure 3). The homology of RSV-A was relatively high (over $80 \%$ ), while it was quite low for other viruses and all species 
Table 3 Subtypes or species of detected viruses

\begin{tabular}{|c|c|c|c|c|}
\hline & & No history of wheezing and/or asthma & & Having history of wheezing and/or asthma \\
\hline Virus & $\begin{array}{l}\text { No. of } \\
\text { strains }\end{array}$ & Strain name & $\begin{array}{l}\text { No. of } \\
\text { strains }\end{array}$ & Strain name \\
\hline RSV-A & 25 & $\begin{array}{c}\text { RSV/YOK/07/14(AB551036), RSV/YOK/07/22(AB551037), RSV/ } \\
\text { YOK/07/26(AB551038), RSV/YOK/07/43(AB551039), RSV/YOK } \\
07 / 51 \text { (AB551040), RSV/YOK/07/52(AB551041), RSV/YOK/07/53 } \\
\text { (AB551042), RSV/YOK/07/66(AB551044), RSV/YOK/08/79 } \\
\text { (AB551046), RSV/YOK/08/83(AB551047), RSV/YOK } 08 / 113 \\
\text { (AB551049), RSV/YOK/08/122(AB551053), RSV/YOK/08/123 } \\
\text { (AB551054), RSV/YOK/08/125(AB551056), RSV/YOK/08/127 } \\
\text { (AB551057), RSV/YOK/08/128(AB551058), RSV/YOK/08/130 } \\
\text { (AB551059), RSV/YOK08/133(AB551060), RSV/YOK/08/134 } \\
\text { (AB551061), RSV/YOK/08/141(AB551065), RSV/YOK } 08 / 142 \\
\text { (AB551066), RSV/YOK/08/146(AB551069), RSV/YOK/08/148 } \\
\text { (AB551071), RSV/YOK08/150(AB551072), RSV/YOK/09/162 } \\
\text { (AB551075) }\end{array}$ & 2 & RSV/YOK/08/73(AB551045), RSV/YOK/08/111(AB551048) \\
\hline RSV-B & 13 & $\begin{array}{c}\text { RSV/YOK/07/13(AB551078), RSV/YOK/07/16(AB551079), RSV/ } \\
\text { YOK/07/17(AB551080), RSV/YOK/07/21(AB551081), RSV/YOK } \\
\text { 07/32(AB551083), RSV/YOK/07/33(AB551084), RSV/YOK/07/34 } \\
\text { (AB551085), RSV/YOK/07/38(AB551086), RSV/YOK/07/50 } \\
\text { (AB551092), RSV/YOK/07/56(AB551093), RSV/YOK/07/60 } \\
\text { (AB551095), RSV/YOK07/62(AB551096), RSV/YOK/07/64 } \\
\text { (AB551097) }\end{array}$ & 7 & $\begin{array}{c}\text { RSV/YOK/07/4(AB551076), RSV/YOK/07/59(AB551094), RSV/ } \\
\text { YOK/08/74(AB551102), RSV/YOK/08/80(AB551104), RSV/YOK } \\
\text { 08/82(AB551105), RSV/YOK/08/84(AB551106), RSV/YOK/08/88 } \\
\text { (AB551107) }\end{array}$ \\
\hline Subtotal & 38 & & 9 & \\
\hline HRV-A & 5 & $\begin{array}{l}\text { HRV/YOK/07/7(AB550346), HRV/YOK/07/61(AB550365), HRV/ } \\
\text { YOK/08/107(AB550377), HRV/YOK/08/110(AB550379), HRV/ } \\
\text { YOK08/112(AB550380) }\end{array}$ & 12 & $\begin{array}{c}\text { HRV/YOK/07/11(AB550348), HRV/YOK/07/15(AB550350), HRV/ } \\
\text { YOK/07/19(AB550352), HRV/YOK/07/24(AB550355), HRV/YOK } \\
\text { 07/25(AB550356), HRV/YOK/07/36(AB550358), HRV/YOK/08/ } \\
\text { 103(AB550374), HRV/YOK/08/131(AB550389), HRV/YOK/08/ } \\
\text { 153(AB550396), HRV/YOK08/167(AB550402), HRV/YOK/08/ } \\
\text { 169(AB550403), HRV/YOK/08/171(AB550404) }\end{array}$ \\
\hline HRV-B & 1 & HRV/YOK/08/129(AB550389) & 1 & HRV/YOK/08/154(AB550397) \\
\hline HRV-C & 6 & $\begin{array}{c}\text { HRV/YOK/07/5(AB550345), HRV/YOK/07/20(AB550356), HRV/ } \\
\text { YOK/07/41(AB550368), HRV/YOK/08/100(AB550379), HRV/ } \\
\text { YOK/09/163(AB550400), HRV/YOK/09/164(AB550401) }\end{array}$ & 11 & $\begin{array}{c}\text { HRV/YOK/07/2(AB550343), HRV/YOK/07/10(AB550347), HRV/ } \\
\text { YOK/07/12(AB550349), HRV/YOK/07/18(AB550351), HRV/YOK } \\
\text { 07/23(AB550353), HRV/YOK/07/55(AB550371), HRV/YOK/08/ } \\
\text { 86(AB550377), HRV/YOK/08/106(AB550382), HRV/YOK/08/120 } \\
\text { (AB550386), HRV/YOK/08/126(AB550388), HRV/YOK/08/159 } \\
\text { (AB550398) }\end{array}$ \\
\hline Subtotal & 12 & & 24 & \\
\hline $\begin{array}{l}\text { RSV-A } \\
+ \text { HRV-A }\end{array}$ & 2 & $\begin{array}{l}\text { RSV/YOK/08/116(AB551050) + HRV/YOK/08/116(AB550381), } \\
\text { RSV/YOK/08/145(AB551068) + HRV/YOK/08/145(AB550392) }\end{array}$ & 3 & $\begin{array}{l}\text { RSV/YOK/07/1(AB551033) + HRV/YOK/07/1(AB550342), RSV/ } \\
\text { YOK/08/117(AB551051) + HRV/YOK/08/117(AB550382), RSV/ } \\
\text { YOK08/119(AB551052) + HRV/YOK/08/119(AB550384) }\end{array}$ \\
\hline $\begin{aligned} & \text { RSV-A } \\
&++H R V-B \\
&\end{aligned}$ & & ND & 1 & RSV/YOK/08/140(AB551064) + HRV/YOK/08/140(AB550392) \\
\hline $\begin{aligned} & \text { RSV-A } \\
+ & \text { HRV-C }\end{aligned}$ & & ND & 1 & RSV/YOK/07/3(AB551034) + HRV/YOK/07/3(AB550344) \\
\hline $\begin{aligned} & \text { RSV-B } \\
&+ \text { HRV-A } \\
&\end{aligned}$ & 2 & $\begin{array}{l}\text { RSV/YOK/07/42(AB551087) + HRV/YOK/07/42(AB550361), } \\
\text { RSV/YOK/07/47(AB551090) + HRV/YOK/07/47(AB550363) }\end{array}$ & & ND \\
\hline $\begin{aligned} & \text { RSV-B } \\
+ & \text { HRV-B }\end{aligned}$ & 1 & RSV/YOK/08/118(AB551108) + HRV/YOK/08/118(AB550363) & & ND \\
\hline $\begin{aligned} & \text { RSV-B } \\
+ & \text { HRV-C }\end{aligned}$ & 4 & $\begin{array}{l}\text { RSV/YOK/07/28(AB551082) + HRV/YOK/07/28(AB550365), } \\
\text { RSV/YOK/07/45(AB551088) + HRV/YOK/07/45(AB550405), } \\
\text { RSV/YOK/07/46(AB551089) + HRV/YOK/07/46(AB550370), } \\
\text { RSV/YOK/07/67(AB551099) + HRV/YOK/07/67(AB550375) }\end{array}$ & & ND \\
\hline Subtotal & 9 & & 5 & \\
\hline $\begin{array}{l}\text { HMPV- } \\
\text { B2 }\end{array}$ & 1 & HMPV/YOK/07/44(AB565438) & & ND \\
\hline HPIV-1 & & ND & 1 & HPIV/YOK/08/115(AB565748) \\
\hline Total & 60 & & 39 & \\
\hline
\end{tabular}

RSV-A, Respiratory syncytial virus subgroup A;RSV-B, Respiratory syncytial virus subgroup B; HRV-A, Human rhinovirus species A; HRV-B, Human rhinovirus species B; HRV-C, Human rhinovirus species C; HMPV, Human metapneumovirus; HPIV-1, Human parainfluenza virus type 1; ND, Not detected 


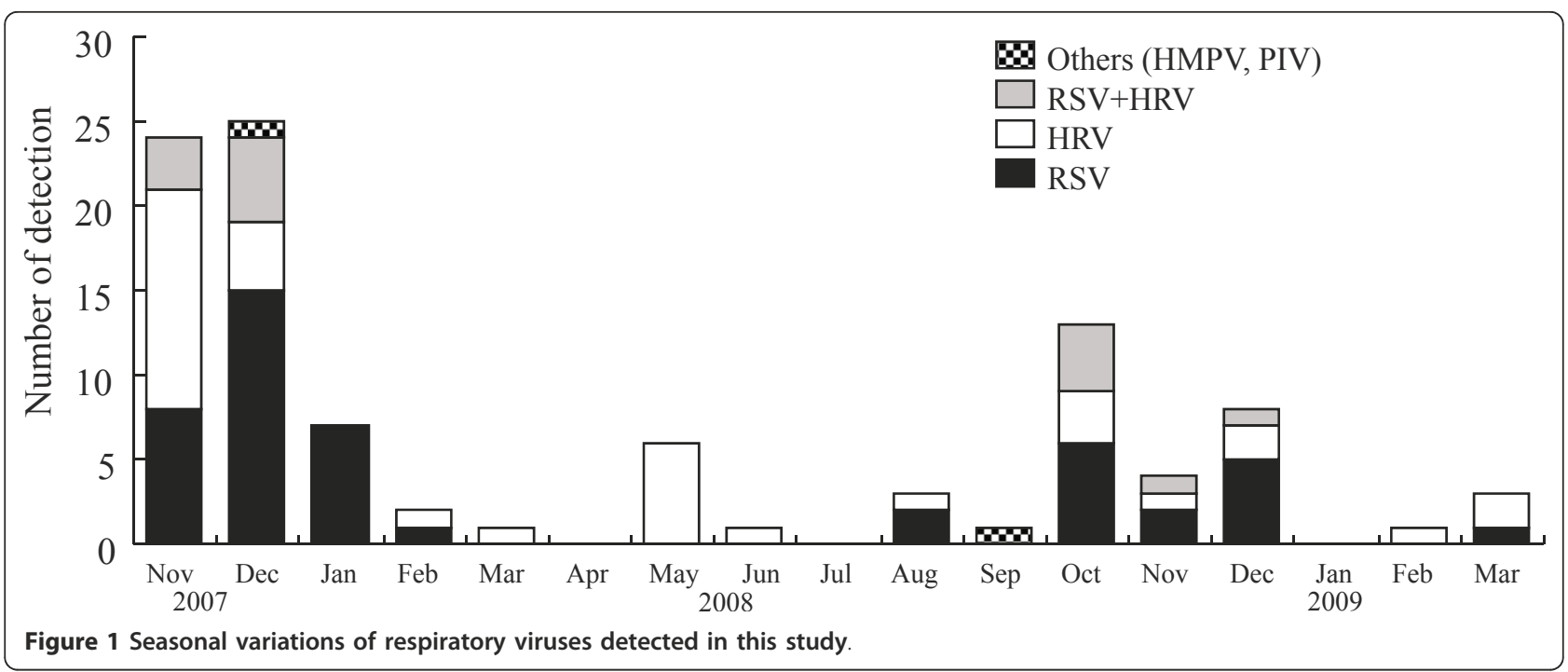

of HRV (over $30 \%$ divergence). Notably, the genetic diversity of HRV-C was wide (52 to 100\%). In addition, the pairwise distances of HRV-A and HRV-C strains are high (over 0.2), while those for RSV-A and RSV-B strains are low. Based on these results it is suggested that acute wheezing-associated HRV has wide genetic diversity.

\section{Discussion}

We detected and genetically analyzed major ARI viruses including RSV, HRV, HMPV, and HPIV in samples from 115 Japanese children with acute wheezing during a 17-month period (November 2007 and March 2009). These viruses were detected in over $80 \%$ of the patients. The dominant viruses were RSV and HRV, and both were detected in over $10 \%$ of the patients. In addition, these viruses were confirmed as belonging to various subgroups, genotypes, or species. All three species of HRV detected showed wide genetic diversity (more than $30 \%$ divergence). Interestingly, RSV was the dominant species detected in patients with no history of wheezing and/or asthma, while HRV was dominant in patients with a history of wheezing and/or asthma. The results suggested that RSV and HRV were major ARI viruses regarding virus-induced acute wheezing in the present study.

It is suggested that various respiratory viruses such as RSV, HRV, HMPV, HPIV, EV, InfV, AdV, and HBoV are detected in patients with lower respiratory tract infections including bronchiolitis and pneumonia [6,7]. These viruses are also detected in cases of acute wheezing $[6,7]$. Thus, they may be associated with both lower respiratory tract infection and acute wheezing in children $[6,7]$. At present, this disease status is recognized by physician and pediatrician as virus-induced asthma
$[28,29]$. It may be important to address the genetic properties of ARI viruses associated with these diseases. However, few studies have been conducted into the genetic analysis of these viruses in acute wheezing. To better understand the relationships between viral properties and acute wheezing, it may be important to genetically analyze ARI viruses detected in the wheezy children. We studied the molecular epidemiology of these respiratory viruses detected in Japanese children with acute wheezing. To the best of our knowledge, the present study is the first to report the detection of RSV, and HRV-A, -B, - C with different genetic characteristics in Japanese children with acute wheezing.

Many studies suggest that RSV is a major candidate as an inducer of acute wheezing $[4,10,11]$ and it may infect all children under the age of 2 years [10,11]. Furthermore, some of these children may develop bronchiolitis and/or pneumonia with acute wheezing [10]. Sugai-Goto et al. demonstrated that genotypes and the major genes $(F, G$, and $N$ ) of RSV isolated from hospitalized children with bronchiolitis or bronchopneumonia accompanied by acute wheezing were not significantly different when compared with RSV strains detected from upper respiratory tract infections [27]. These viruses belong to subgroup A, genotype GA2 and subgroup B, genotype BA [27]. Furthermore, Nakamura et al. showed similar genetic data from various acute respiratory infections in Okinawa, Japan [30]. Our findings regarding the properties of $G$ gene in the RSV strains detected were comparable with the abovementioned reports. In contrast, it has been suggested that a specific genotype, GA3 type virus, might be associated with a significantly greater severity of illness [31]. Riccetto et al. demonstrated that the severity of illness of RSV infection in infants can be associated with other factors such as body weight and prematurity [32], and any 


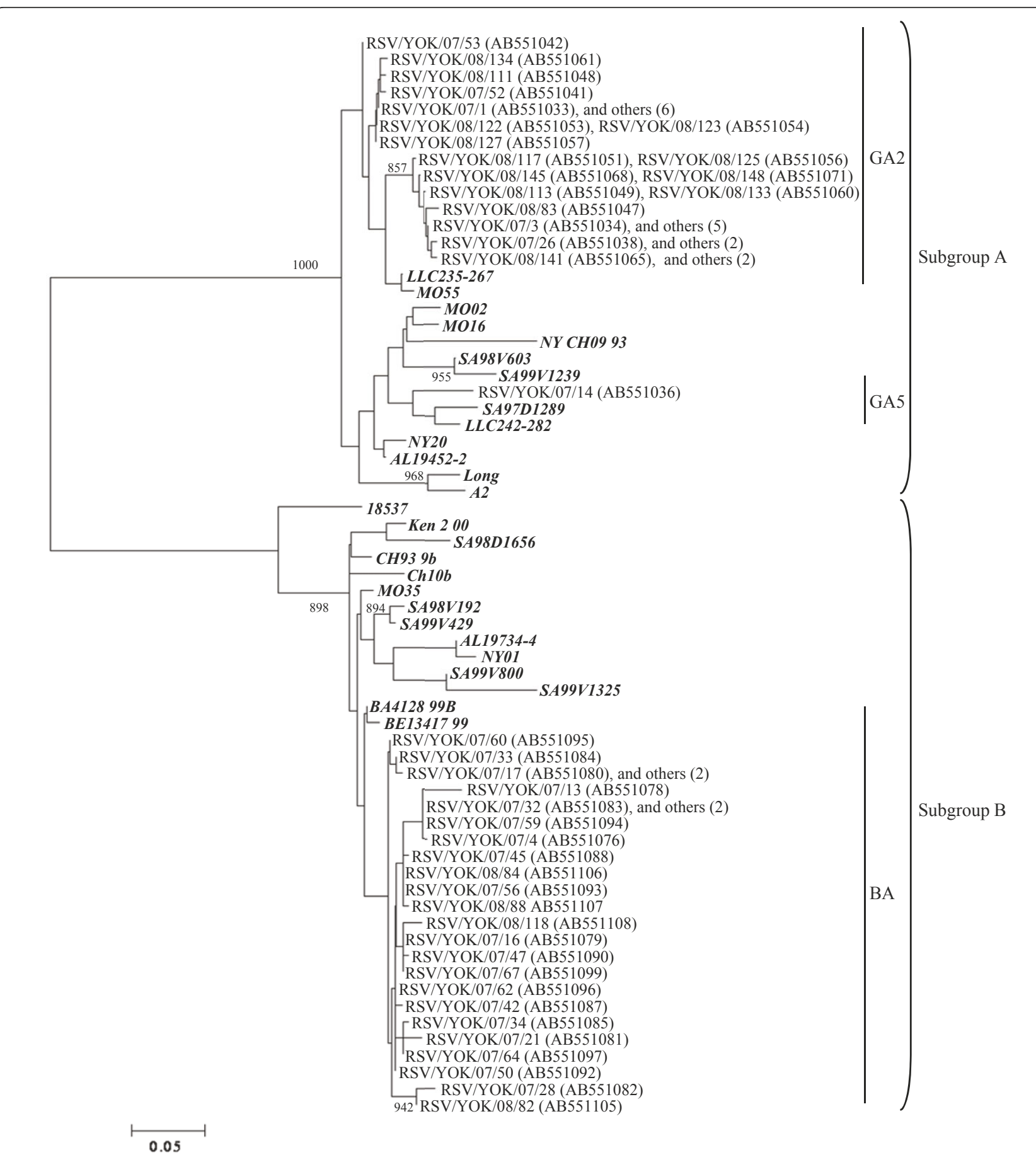

Figure 2 Phylogenetic analysis of RSV ( $G$ gene). Detailed procedures and conditions of the phylogenetic tree are shown in the text. Numbers in parentheses indicate numbers of strains detected in other patients. Reference strains are shown in bold type. Bars, 0.05 substitutions per nucleotide position. Only bootstrap values more than $85 \%$ are shown at branch points.

association between the viral properties and pathogenicity of RSV has yet to be elucidated. Another report suggested that host immunity such as TLR4 polymorphism is linked to symptomatic RSV [33]. Thus, both the antigenicity of the viruses and host immune conditions may play important roles in the pathophysiology of severe respiratory infections such as bronchiolitis, pneumonia, and virus-induced asthma $[1,34]$.

For a long time, HRV was simply thought to be causative agents of the mild common cold [12]. In general, 


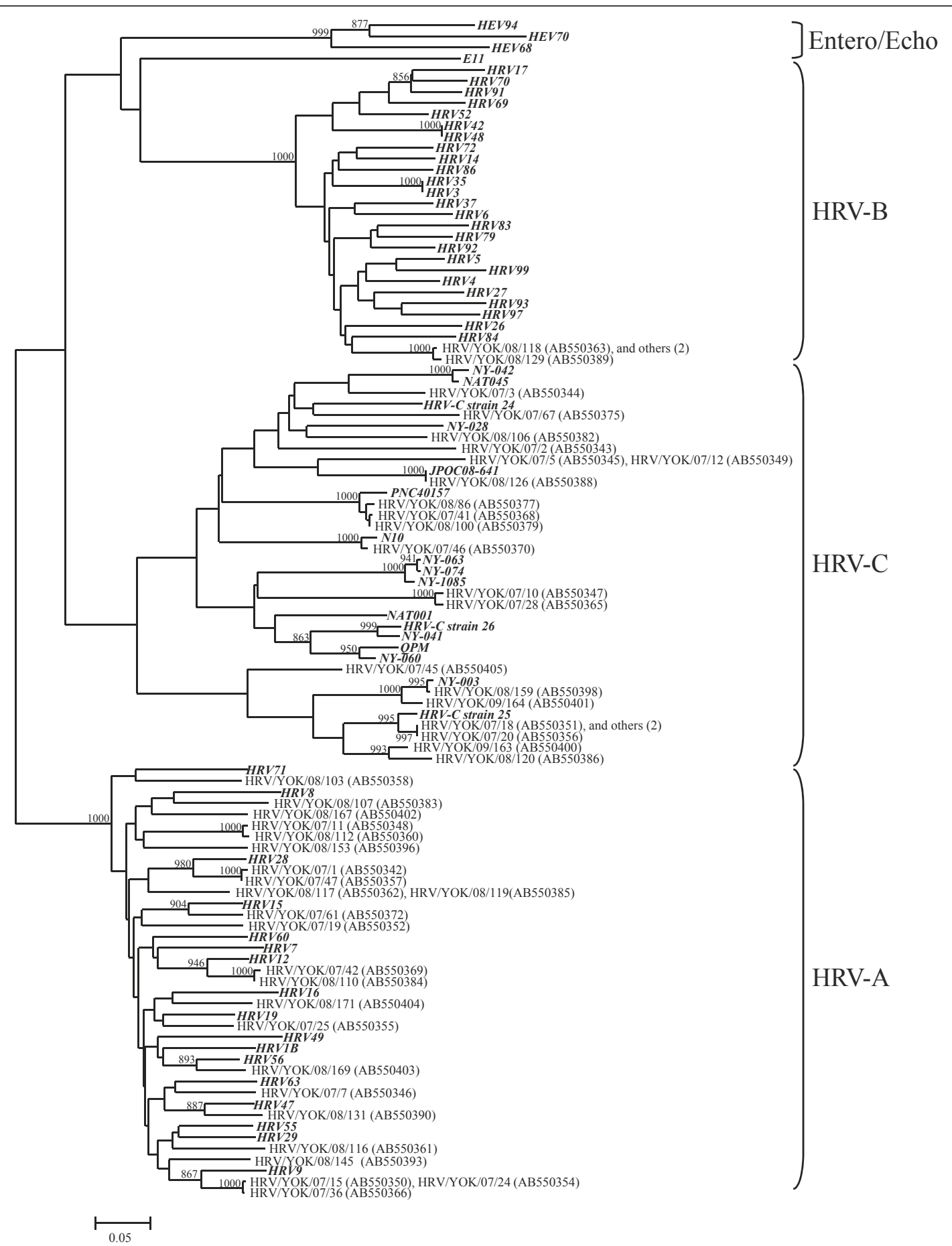

Figure 3 Phylogenetic analysis of HRV (VP4/NP2 coding region). Detailed procedures and conditions of the phylogenetic tree are shown in the text. Numbers in parentheses indicate numbers of strains detected in other patients. Reference strains are shown in bold type. Bars, 0.05 substitutions per nucleotide position. Only bootstrap values more than $85 \%$ are shown at branch points.

this acknowledgement may not be incorrect in nonasthmatic people [35]. However, it is suggested that HRV induces wheezing and exacerbation of symptoms in most asthmatics [12]. However, the molecular epidemiology of each HRV species is not yet known, because HRV is relatively difficult to isolate and detect. Thus, non-culturable HRV-C was only recovered a few years ago. Very recently, Mizuta et al. demonstrated 
Table 4 Pairwise distances and homology of RSV and HRV strains based on nucleotide sequences

\begin{tabular}{|c|c|c|c|c|}
\hline & $\begin{array}{c}\text { Homology } \\
\text { (\%) }\end{array}$ & & $\begin{array}{l}\text { Pairwise } \\
\text { distance }\end{array}$ & \\
\hline Virus & All strains* & $\begin{array}{l}\text { Present } \\
\text { strains }^{* *}\end{array}$ & All strains* & $\begin{array}{l}\text { Present } \\
\text { strains }^{* *}\end{array}$ \\
\hline $\begin{array}{c}\text { RSV- } \\
\text { A }\end{array}$ & $82.0-100$ & $83.5-100$ & $0.063 \pm 0.043$ & $0.035 \pm 0.034$ \\
\hline $\begin{array}{c}\text { RSV- } \\
\text { B }\end{array}$ & $74.2-100$ & $92.8-100$ & $0.060 \pm 0.040$ & $0.029 \pm 0.014$ \\
\hline $\begin{array}{l}\text { HRV- } \\
\text { A }\end{array}$ & $66.4-100$ & $66.5-100$ & $0.202 \pm 0.031$ & $0.200 \pm 0.038$ \\
\hline $\begin{array}{l}\text { HRV- } \\
\text { B }\end{array}$ & $68.1-100$ & $99.5-100$ & $0.204 \pm 0.039$ & $0.002 \pm 0.003$ \\
\hline $\begin{array}{l}\text { HRV- } \\
\text { C }\end{array}$ & $41.0-100$ & $52.2-100$ & $0.263 \pm 0.069$ & $0.254 \pm 0.077$ \\
\hline
\end{tabular}

Data are expressed as mean $\pm S D$

RSV-A, Respiratory syncytial virus subgroup A

RSV- $B$, Respiratory syncytial virus subgroup $B$

HRV-A, Human rhinovirus species A

HRV-B, Human rhinovirus species $B$

HRV-C, Human rhinovirus species $C$

* All strains: reference strains plus the strains detected in the present study.

** Present strains: viruses detected in the present study.

that HRV-A isolates showed wide genetic diversity, and some viruses belonging to specific clusters of the phylogenetic tree of HRV-A isolates might be associated with bronchiolitis [17]. In addition, a new study suggested that HRV-C has a stronger link to virus-induced asthma than HRV-A and -B strains [36]. However, our results did not reveal a similar tendency, although the reasons for this are unknown.

In this study, both RSV and HRV were detected from over $10 \%$ of patients with acute wheezing. Chung et al. demonstrated that both RSV and HRV were detected in $3.9 \%$ of Korean children with acute wheezing [37]. Thus, our data and that of other studies may be comparable, although the percentages of virus detection differ. We additionally compared the severity of clinical symptoms between dual virus-detected patients and those in whom RSV or HRV was detected alone. However, there were no significant findings. In addition, RSV, HRV, HMPV, HPIV, EV, InfV, AdV, and HBoV were not detected in over $10 \%$ of patients. Although we were unable to explain why, it might be that other respiratory viruses and bacteria were involved.

It should be noted that some respiratory viruses might be detected in healthy children [1,38-40]. As mentioned above, various species of HRV have been relatively frequently detected in healthy children (around 10-20\%) $[39,40]$, although RSV was detected less frequently in healthy and asymptomatic persons [40]. Thus, to better understand the etiology of these viruses, it may be important to determine the prevalence of these viruses in healthy children. A limitation of this study is that we did not examine such prevalence in healthy children and instead focused mainly on detailed molecular epidemiological analysis of various respiratory viruses detected in children with acute wheezing. Additional molecular epidemiological studies of viruses detected in wheezy and healthy children would be of value.

In the present study, HMPV and HPIV were detected in samples from the subjects, albeit rarely (each virus was detected in one of only two patients). It is suggested that HMPV and HPIV are also associated with bronchiolitis and bronchopneumonia [41]. However, it is not known how these viruses are linked to the induction of wheezing and exacerbation of asthma [42]. A previous study suggested that sputum from HPIV infection contains tryptase due to activation (degranulation) of mast cells, and this activation may strongly induce an asthmatic attack [43]. Thus, HPIV infection may induce asthmatic conditions [7]. Additional studies regarding the relationships between HPIV and HMPV infection and virus-induced asthma are warranted.

\section{Conclusions}

Our data suggested that both RSV and HRV with various genetic characteristics were associated with acute wheezing illness in Japanese children. In particular, HRV shows widely genetic diversity. Larger studies to examine the detailed genetic characteristics of the various respiratory viruses detected in wheezy and healthy children may be needed.

\section{Abbreviations}

RSV: respiratory syncytial virus; HRV: human rhinovirus; HMPV: human metapneumovirus; HPIV: human parainfluenza virus; EV: enterovirus; InfV: influenza viruses; AdV: adenoviruses; HBoV: human bocavirus; DDBJ: DNA Data Bank of Japan; NJ: neighbor-joining

\section{Acknowledgements}

We thank Drs. Hirotaka Motoi and Yoshinori Kobayashi for constructive discussion. This work was supported by a Grant-in-Aid from the Japan Society for Promotion of Science and for Research on Emerging and Reemerging Infectious Diseases from the Ministry of Health, Labour and Welfare.

\section{Author details}

${ }^{1}$ Department of Pediatrics, National Hospital Organization Yokohama Medical Center, 3-60-2 Harajuku, Totsuka-ku, Yokohama, Kanagawa 245-8575, Japan. 2Department of Pediatrics, Yokohama City University Graduate School of Medicine, 3-9 Fukuura, Kanazawa-ku, Yokohama, Kanagawa 236-0004, Japan. ${ }^{3}$ Department of Health Science, Gunma Prefectural Institute of Public Health and Environmental Sciences, 378 Kamioki-machi, Maebashi-shi, Gunma 3710052, Japan. ${ }^{4}$ Department of Microbiology, Tochigi Prefectural Institute of Public Health, 2154-13 Shimo-okamoto, Utsunomiya-shi, Tochigi 329-1196, Japan. ${ }^{5}$ Department of Molecular Biodefence Research, Yokohama City University Graduate School of Medicine, 3-9 Fukuura, Kanazawa-ku, Yokohama, Kanagawa 236-0004, Japan. ${ }^{6}$ Division of Molecular Cell Immunology and Allergology, Advanced Medical Research Center, Nihon University, Graduate School of Medical Science, 30-1 Oyaguchi-kamimachi, Itabashi-ku, Tokyo 173-8610, Japan. Department of Microbiology, Yamagata Prefectural Institute of Public Health, 1-6-6 Toka-machi, Yamagata-shi, Yamagata 990-0031, Japan. ${ }^{8}$ Department of Health and Nutrition, Yamagata Prefectural Yonezawa Women's Junior College, 6-15-1Tori-machi, Yonezawa- 
shi, Yamagata 992-0025, Japan. ${ }^{9}$ Department of Virology III, National Institute of Infectious Diseases, 4-7-1 Gakuen, Musashimurayama-shi, Tokyo 208-0011, Japan. ${ }^{10}$ Influenza Virus Research Center, National Institute of Infectious Diseases, 4-7-1 Gakuen, Musashimurayama-shi, Tokyo 208-0011, Japan. ${ }^{11}$ Infectious Disease Surveillance Center, National Institute of Infectious Diseases, 4-7-1 Gakuen, Musashimurayama-shi, Tokyo 208-0011, Japan.

\section{Authors' contributions}

AF, HK, HT, MT, SY, and NO designed research; MA, KGS, HT, KM, MN, MY, and AN performed research; HT, AF, and MA contributed analytic tools, HK, $A R, Y O, Y K$, and $M M$ analyzed data; $H K, H T$, and $Y O$ wrote the paper. All authors read and approved the final manuscript.

\section{Competing interests}

The authors declare that they have no competing interests. The authors alone are responsible for the content and writing of the paper.

Received: 9 February 2011 Accepted: 10 June 2011

Published: 10 June 2011

\section{References}

1. Tregoning JS, Schwarze J: Respiratory viral infections in infants: causes, clinical symptoms, virology, and immunology. Clin Microbiol Rev 2010, 23(1):74-98.

2. Monto AS: Occurrence of respiratory virus: time, place and person. Pediatr Infect Dis J 2004, 23(1 Suppl):S58-64.

3. Fabbiani M, Terrosi C, Martorelli B, Valentini M, Bernini L, Cellesi C, Cusi MG: Epidemiological and clinical study of viral respiratory tract infections in children from Italy. J Med Virol 2009, 81(4):750-6.

4. Busse $\mathrm{WW}$, Lemanske RF Jr, Gern JE: Role of viral respiratory infections in asthma and asthma exacerbations. Lancet 2010, 376(9743):826-34.

5. Braman SS: The global burden of asthma. Chest 2006, 130(1 Suppl):4S-12S

6. Pierangeli A, Gentile M, Di Marco P, Pagnotti P, Scagnolari C, Trombetti S, Lo Russo L, Tromba V, Moretti C, Midulla F, Antonelli G: Detection and typing by molecular techniques of respiratory viruses in children hospitalized for acute respiratory infection in Rome, Italy. J Med Virol 2007, 79(4):463-8.

7. Kusel MM, de Klerk NH, Kebadze T, Vohma V, Holt PG, Johnston SL, Sly PD: Early-life respiratory viral infections, atopic sensitization, and risk of subsequent development of persistent asthma. J Allergy Clin Immunol 2007, 119(5):1105-10.

8. Kato M, Tsukagoshi H, Yoshizumi M, Saitoh M, Kozawa K, Yamada Y, Maruyama $K$, Hayashi $Y$, Kimura H: Different cytokine profile and eosinophil activation are involved in rhinovirus- and RS virus-induced acute exacerbation of childhood wheezing. Pediatr Allergy Immunol 2011, 22(1 Pt 2):e87-94.

9. Kuehni CE, Spycher BD, Silverman M: Causal links between RSV infection and asthma: no clear answers to an old question. Am J Respir Crit Care Med 2009, 179(12):1079-80.

10. Cane PA: Molecular epidemiology of respiratory syncytial virus. Rev Med Virol 2001, 11(2):103-16.

11. Mackay IM: Human rhinoviruses: the cold wars resume. J Clin Virol 2008, 42(4):297-320.

12. Turner RB, Couch RB: Rhinoviruses. In Fields Virology.. 5 edition. Edited by: Knipe DM, Howley PM, Griffin DE, Lamb RA, Martin MA, Roizman B, Straus SE. Philadelphia: Lippincott Williams 2007:895-909.

13. Henrickson KJ: Parainfluenza viruses. Clin Microbiol Rev 2003, 16(2):242-64.

14. Kahn JS: Newly discovered respiratory viruses: significance and implications. Curr Opin Pharmacol 2007, 7(5):478-83.

15. Piralla A, Rovida F, Campanini G, Rognoni V, Marchi A, Locatelli F, Gerna G Clinical severity and molecular typing of human rhinovirus $C$ strains during a fall outbreak affecting hospitalized patients. J Clin Virol 2009, 45(4):311-7.

16. Hishinuma-lgarashi I, Mizuta K, Saito Y, Ohuchi Y, Noda M, Akiyama M, Sato H, Tsukagoshi H, Okabe N, Tashiro M, Kimura H: Phylogenetic analysis of human bocavirus ( $\mathrm{HBOV}$ ) detected from children with acute respiratory infection in Japan. J Infect 2009, 58(4):311-3.

17. Mizuta $K$, Hirata A, Suto A, Aoki Y, Ahiko T, Itagaki T, Tsukagoshi H, Morita Y, Obuchi M, Akiyama M, Okabe N, Noda M, Tashiro M, Kimura H: Phylogenetic and cluster analysis of human rhinovirus species A (HRV-A) isolated from children with acute respiratory infections in Yamagata, Japan. Virus Res 2010, 147(2):265-74.

18. Parveen S, Sullender WM, Fowler K, Lefkowitz EJ, Kapoor SK, Broor S: Genetic variability in the $G$ protein gene of group $A$ and $B$ respiratory syncytial viruses from India. J Clin Microbiol 2006, 44(9):3055-64.

19. Ishiko H, Shimada Y, Yonaha M, Hashimoto O, Hayashi A, Sakae K, Takeda N: Molecular diagnosis of human enteroviruses by phylogeny-based classification by use of the VP4 sequence. J Infect Dis 2002, 185(6):744-54.

20. Olive DM, Al-Mufti S, Al-Mulla W, Khan MA, Pasca A, Stanway G, Al-Nakib W: Detection and differentiation of picornaviruses in clinical samples following genomic amplification. J Gen Virol 1990, 71(Pt 9):2141-7.

21. Takao S, Shimozono H, Kashiwa H, Matsubara K, Sakano T, Ikeda M, Okamoto N, Yoshida H, Shimazu Y, Fukuda S: The first report of an epidemic of human metapneumovirus infection in Japan: clinical and epidemiological study. Kansenshogaku Zasshi 2004, 78(2):129-37.

22. Echevarría JE, Erdman DD, Swierkosz EM, Holloway BP, Anderson L: Simultaneous detection and identification of human parainfluenza viruses 1,2, and 3 from clinical samples by multiplex PCR. J Clin Microbiol 1998, 36(5):1388-91.

23. WHO information for laboratory diagnosis of pandemic (H1N1) 2009 virus in humans - revised:[http://www.who.int/csr/resources/publications/ swineflu/diagnostic_recommendations/en/index.html].

24. Miura-Ochiai R, Shimada Y, Konno T, Yamazaki S, Aoki K, Ohno S, Suzuki E, Ishiko H: Quantitative detection and rapid identification of human adenoviruses. J Clin Microbiol 2007, 45(3):958-67.

25. Allander T, Tammi MT, Eriksson M, Bjerkner A, Tiveljung-Lindell A, Andersson B: Cloning of a human parvovirus by molecular screening of respiratory tract samples. Proc Natl Acad Sci USA 2005, 102(36):12891-6.

26. Saitou N, Nei M: The neighbor-joining method: a new method for reconstructing phylogenetic trees. Mol Biol Evol 1987, 4(4):406-25.

27. Goto-Sugai K, Tsukagoshi H, Mizuta K, Matsuda S, Noda M, Sugai T, Saito Y, Okabe N, Tashiro M, Kozawa K, Tanaka R, Morita Y, Nishina A, Kimura H: Genotyping and phylogenetic analysis of major genes in respiratory syncytial virus isolated from infants with bronchiolitis in Japan. Jpn J Infect Dis 2010, 63(6):393-400.

28. Rosenthal LA, Avila PC, Heymann PW, Martin RJ, Miller EK, Papadopoulos NG, Peebles RS Jr, Gern JE, Infections and Asthma Committee, Environmental and Occupational Respiratory Diseases Interest Section, American Academy of Allergy, Asthma \& Immunology: Viral respiratory tract infections and asthma: the course ahead. $J$ Allergy Clin Immunol 2010, 125(6):1212-7.

29. Gern JE: Mechanisms of virus-induced asthma. J Pediatr 2003, 142(2 Suppl):S9-13, discussion S13-4.

30. Nakamura M, Itokazu K, Taira K, Kawaki T, Kudaka J, Nidaira M, Okano S, Koja Y, Tamanaha K, Kimura H, Noda M: Genotypic and phylogenetic analysis of the $\mathrm{G}$ gene of respiratory syncytial virus isolates in Okinawa, Japan, 2008. Jpn J Infect Dis 2009, 62(4):326-7.

31. Martinello RA, Chen MD, Weibel C, Kahn JS: Correlation between respiratory syncytial virus genotype and severity of illness. J Infect Dis 2002, 186(6):839-42.

32. Riccetto AG, Ribeiro JD, Silva MT, Almeida RS, Arns CW, Baracat EC: Respiratory syncytial virus (RSV) in infants hospitalized for acute lower respiratory tract disease: incidence and associated risks. Braz I Infect Dis 2006, 10(5):357-61

33. Awomoyi AA, Rallabhandi P, Pollin TI, Lorenz E, Sztein MB, Boukhvalova MS, Hemming VG, Blanco JC, Vogel SN: Association of TLR4 polymorphisms with symptomatic respiratory syncytial virus infection in high-risk infants and young children. J Immunol 2007, 179(5):3171-7.

34. Collins PL, Graham BS: Viral and host factors in human respiratory syncytial virus pathogenesis. J Virol 2008, 82(5):2040-55.

35. Rawlinson WD, Waliuzzaman Z, Carter IW, Belessis YC, Gilbert KM, Morton JR: Asthma exacerbations in children associated with rhinovirus but not human metapneumovirus infection. J Infect Dis 2003, 187(8):1314-8.

36. Miller EK, Edwards KM, Weinberg GA, Iwane MK, Griffin MR, Hall CB, Zhu Y Szilagyi PG, Morin LL, Heil LH, Lu X, Williams JV, New Vaccine Surveillance Network: New Vaccine Surveillance Network. A novel group of rhinoviruses is associated with asthma hospitalizations. J Allergy Clin Immunol 2009, 123(1):98-104. 
37. Chung JY, Han TH, Kim SW, Kim CK, Hwang ES: Detection of viruses identified recently in children with acute wheezing. J Med Virol 2007, 79(8):1238-43.

38. Calvo C, Casas I, García-García ML, Pozo F, Reyes N, Cruz N, GarcíaCuenllas L, Pérez-Breña P: Role of rhinovirus $C$ respiratory infections in sick and healthy children in Spain. Pediatr Infect Dis J 2010, 29(8):717-20.

39. Winther B, Hayden FG, Hendley JO: Picornavirus infections in children diagnosed by RT-PCR during longitudinal surveillance with weekly sampling: Association with symptomatic illness and effect of season. $J$ Med Virol 2006, 78(5):644-50.

40. Fairchok MP, Martin ET, Chambers S, Kuypers J, Behrens M, Braun LE, Englund JA: Epidemiology of viral respiratory tract infections in a prospective cohort of infants and toddlers attending daycare. J Clin Virol 2010, 49(1):16-20.

41. Williams JV, Edwards KM, Weinberg GA, Griffin MR, Hall CB, Zhu Y, Szilagyi PG, Wang CK, Yang CF, Silva D, Ye D, Spaete RR, Crowe JE Jr: Population-based incidence of human metapneumovirus infection among hospitalized children. J Infect Dis 2010, 201(12):1890-8.

42. Mallia P, Johnston SL: How viral infections cause exacerbation of airway diseases. Chest 2006, 130(4):1203-10.

43. Nagayama Y, Tsubaki T, Toba T, Nakayama S, Kiyofumi O: Analysis of sputum taken from wheezy and asthmatic infants and children, with special reference to respiratory infections. Pediatr Allergy Immunol 2001, 12(6):318-26.

\section{Pre-publication history}

The pre-publication history for this paper can be accessed here: http://www.biomedcentral.com/1471-2334/11/168/prepub

doi:10.1186/1471-2334-11-168

Cite this article as: Fujitsuka et al:: A molecular epidemiological study of respiratory viruses detected in Japanese children with acute wheezing illness. BMC Infectious Diseases 2011 11:168.

\section{Submit your next manuscript to BioMed Central and take full advantage of:}

- Convenient online submission

- Thorough peer review

- No space constraints or color figure charges

- Immediate publication on acceptance

- Inclusion in PubMed, CAS, Scopus and Google Scholar

- Research which is freely available for redistribution

Submit your manuscript at www.biomedcentral.com/submit
Biomed Central 